\title{
THE ESTABLISHING OF THE INSERTION LOSS OF THE NOISE BARRIERS
}

\author{
RADOI, A. M.
}

Abstract : Over the past 40 years, much effort has been placed into developing more accurate modelling tools for determining the acoustic performance of barriers for road noise attenuation. In many previous analyses the insertion loss has been referred to as indicative of the overall barrier performance. This paper presents three methods for determining the insertion loss of the noise barriers. Insertion loss values obtained by the program ENC are compared with the values obtained by calculation using formulas and with the values obtained by modeling the noise barriers with specialized software CadnaA. These three methods will be tested on a case study, where an important traffic road crosses a residential area.The aim of this paper is not to assess the noise impact on the residential buildings, but to compare the noise reduction that can be obtained installing acoustical barriers, with different calculation methods. Results will show that the three methods confirm the better performances of a higher barrier, but it will be shown that types of barriers and other parameters have to be carefully taken into account to avoid incorrect evaluation.

Key words: noise barrier, insertion loss, noise level, traffic noise, urban acoustics
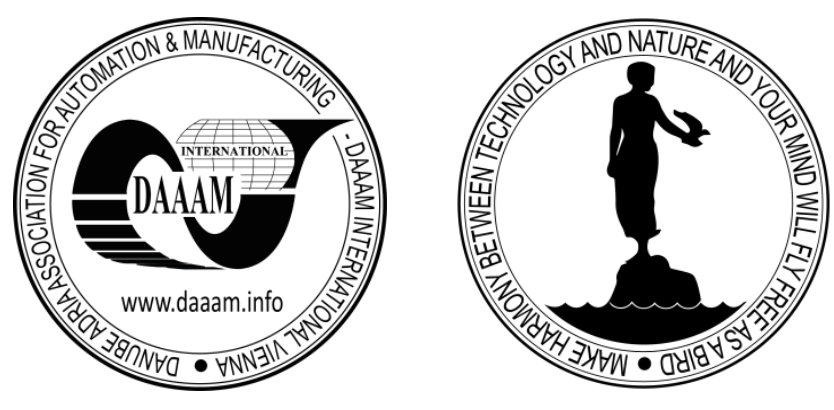

Author data: $\mathrm{PhD}$ student Radoi, A[lina], M[ihaela], University Politehnica of Bucharest, Dept. of Mechanics, 313 Splaiul Independentei, Bucharest, Romania, ralina_upb@yahoo.com

This Publication has to be referred as: Radoi, A[lina Mihaela] (2015). The Establishing of the Insertion Loss of the Noise Barriers, Chapter 16 in DAAAM International Scientific Book 2015, pp.173-188, B. Katalinic (Ed.), Published by DAAAM International, ISBN 978-3-902734-05-1, ISSN 1726-9687, Vienna, Austria DOI: $10.2507 /$ daaam.scibook.2015.16 


\section{Introduction}

Noise barriers are commonly used to attenuate road traffic noise. A barrier functions by blocking the line-of- sight between a noise source and a receiver, thus creating a sound shadow zone. When a noise barrier is inserted between a noise source and a receiver, the direct noise is reflected, transmitted and diffracted. Noise barriers generally provide more effective attenuation at high frequencies as short wavelengths are not as easily diffracted into the shadow zone. Barrier performance is measured by its insertion loss defined as the difference in sound pressure level before and after the barrier is constructed.

The first attempt of modelling of the insertion loss of the thin barriers was performed by Maekawa, using the number of Fresnel. There followed Kurze, Anderson, Maekawa et al. for finite length screens. Egan et al. investigated the superior edges of the barriers and the manner to improve the attenuation of the noise from these barriers which use different forms and have different lengths. Bies and Hansen calculated the insertion loss of the barriers in free field according to ISO 9613-2, ISO 10847 and ISO 11821.

Numerical BE models have been developed to calculate barrier efficiency (Seznec, 1980), to assess the acoustic performance of a range of barrier designs (Hothersall et al., 1991a; Ishizuka and Fujiwara, 2004), to model diffusive barriers (Naderzadeh et al., 2011), and for optimisation of the acoustic performance of Tshaped and Y-shaped barriers (Baulac et al., 2008; Greiner et al., 2010).

Each country has usually adopted its own specific method for predicting the performance of barriers for specific transport noise sources. For example in the UK, calculation of the attenuation of road traffic noise by a barrier is performed using a chart in terms of path length difference. In Japan, barrier height is determined by a design chart such as Maekawa's or other specific design chart using a representative spectrum of road traffic noise. When walls in city streets are used as barriers, they must be sound absorbing. In the USA, Stamina/Optima has been the official highway noise prediction and barrier design model. The US Department of Transportation's Federal Highway Administration (FHWA) is developing the next generation of highway noise prediction computer code called the Traffic Noise Model (TNM). In the EU, the standard approach for analyzing a traffic noise problem in an urban area is based on calculations with simple models. First noise levels in the area are calculated with an engineering noise model and next empirical exposure-response relations are applied to estimate the prevalence of annoyance and sleep disturbance. The focus is often on annoyance at home, and therefore the noise levels are calculated at the facades of dwellings.

This paper presents an important traffic road in Bucharest, with vehicles of all categories, in which vicinity a hospital will be built. The closeness of the road to the hospital and the residential buildings, makes the noise levels to their facades to register values which exceed the legal limit. With the specialized programs, CadnaA and ENC, there are presented simulations, through the placing of the noise barriers in parallel with the road lines. Based on the calculation relations, it will be established the insertion loss of the noise barriers. 
Insertion loss values obtained by the program ENC are compared with the values obtained by calculation using formulas and with the values obtained by modeling the noise barriers with specialized software CadnaA.

CadnaA (DataKustik GmbH, Germany) is widely used in Europe for the modeling and prediction of noise maps for cities in accordance with the European Directive on environmental noise (Directive 2002/49/EC of the European Parliament 2002). The current version of the CadnaA 4.3 software includes the option Mithra for different types of noise barriers and the ENC 4.1 software includes outdoor noise barriers.

\section{Methods}

A general objective of the work was to develop a local evaluation methodology of a traffic noise problem close to a protected area.

The methodology consists of the following stages:

\subsection{The modelling of the area with the cadnaA software}

The street has 6 traffic lanes ( 3 traffic lanes for each direction) and the numbering of the vehicles was done for the 2 traffic directions.

At the numbering of the vehicles in the traffic, it was made a distinction between the 2 types of vehicles (light and heavy). For the street there were used the data of the weekly measurements from the Romanian Automobile Register (RAR).

The table 1 shows data traffic registered by the Romanian Auto Register (RAR):

\begin{tabular}{|c|c|c|c|c|c|c|c|c|c|c|c|c|c|c|}
\hline FLD & QVD & VVD & QPD & VPD & FLE & QVE & VVE & QPE & VPE & FLN & QVN & VVN & QPN & VPN \\
\hline 2.1 & 2382 & 30 & 196 & 25 & 2.1 & 1053 & 40 & 48 & 30 & 1.1 & 365 & 50 & 58 & 40 \\
\hline
\end{tabular}

Tab. 1. RAR data

where:

$F L D$-flow type ( day); $Q V D$ - number of the light veh/h (day); $V V D$ - the average speed of the light veh/ h $(\mathrm{km} / \mathrm{h})($ day) $; Q P D$ - number of the heavy veh/ h (day); $V P D$ - the average speed of the heavy veh/h(day)

The method of calculation for traffic with the software Cadna is NMPB-1996 ("Nouvelle Méthode de Prévision du Bruit").

For modeling the road, the traffic flow $Q$ (in vehicle / hour) and the percentage of heavy vehicles $\mathrm{p} \%$ must be specified.

$Q=Q_{V L}+Q_{P L} \quad$ and $\quad p \%=\frac{Q_{P L}}{Q}$

$Q_{V L}$ - number of the light vehicles traffic (max.mass $<3.5 \mathrm{t}$ ), in veh/ $\mathrm{h}$

$Q_{P L}$ - number of the heavy vehicles traffic, in vehicles / hour

$$
\mathrm{Q}=1289 \text { ( number veh./h for } 1 \text { sens of movement) }
$$




$$
\begin{gathered}
\mathrm{p} \%=7.6 \text { daym } \\
\mathrm{Q}=1101(\text { number veh./h ) } \\
\mathrm{p} \%=4.3 \text { evening } \\
\mathrm{Q}=423 \text { (number veh./h) } \\
\mathrm{p} \%=13.7 \text { night }
\end{gathered}
$$

The percentage of heavy vehicles / hour is passed for periods of the day, evening, night: $7.6 \%$ (day), $4.3 \%$ (evening), $13.7 \%$ (night).

It is considered the speed limit of $50 \mathrm{~km} / \mathrm{h}$ for light vehicles and $40 \mathrm{~km} / \mathrm{h}$ for heavy vehicles.

Of the four types of traffic flows, is chosen the pulse non-differentiated.

Horizontal gradient of the road for street and traffic flow pulse is $2.1 \%$.

Because of the fact that on the chosen street there circulate more than 300 vehicles / hour, it is considered the linear source of infinite length.

All these aspects and the 1-6 relations are filled in the dialogue box of the road in figure1.

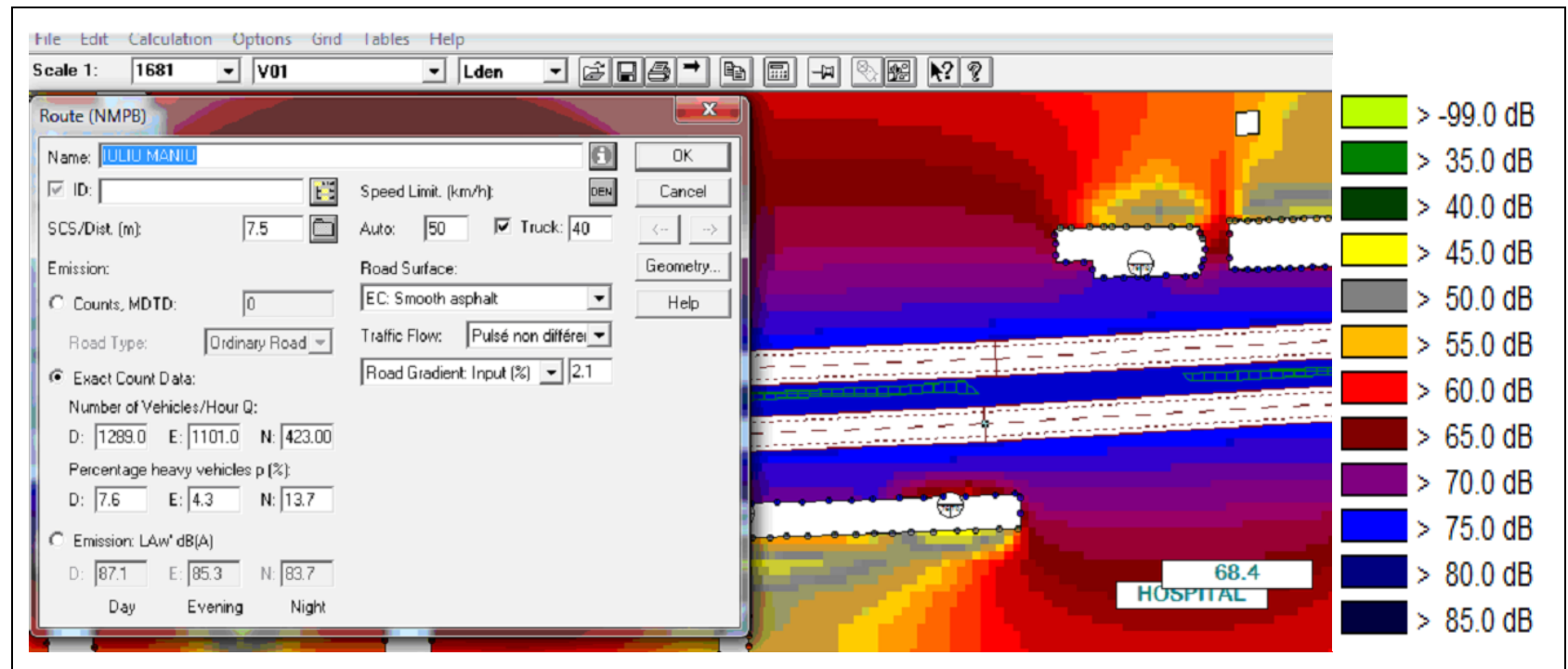

Fig. 1. Modeling area Lden

Colour Legend

The noise map of the area is presented in CadnaA 3D in figure 2 for the period day - evening - night and in figure 3 for the night period. The indicators Lden and Ln are foreseen in the Governmental Decision no. 321/2005 which transposes the Directive 2009/49/EC (END) regarding the environmental noise. Lden (noise indicator for day-evening-night) is the weighted average acoustic level (A) established for 1 year. Ln (noise indicator for day-evening-night) is the weighted average acoustic level (A) established for the total of the night periods in one year.

According to the legend of colors, the facades of the buildings are exposed to noise values which exceed $75 \mathrm{~dB}(\mathrm{~A})$ (blue color) during daytime and $70 \mathrm{~dB}(\mathrm{~A})$ (mauve 
color) during nighttime. According to Order no. 119/2014 of the Ministry of Health, the equivalent continuous level of acoustic pressure $A$ (LAeq), measured outside the building, must not exceed $55 \mathrm{~dB}(\mathrm{~A})$ during daytime and $45 \mathrm{~dB}(\mathrm{~A})$ during nighttime.

For the hospital, according to STAS 100009-88 Urban Acoustics, the equivalent continuous noise level, measured at the boundary functional area, must not exceed 45 $\mathrm{dB}(\mathrm{A})$.

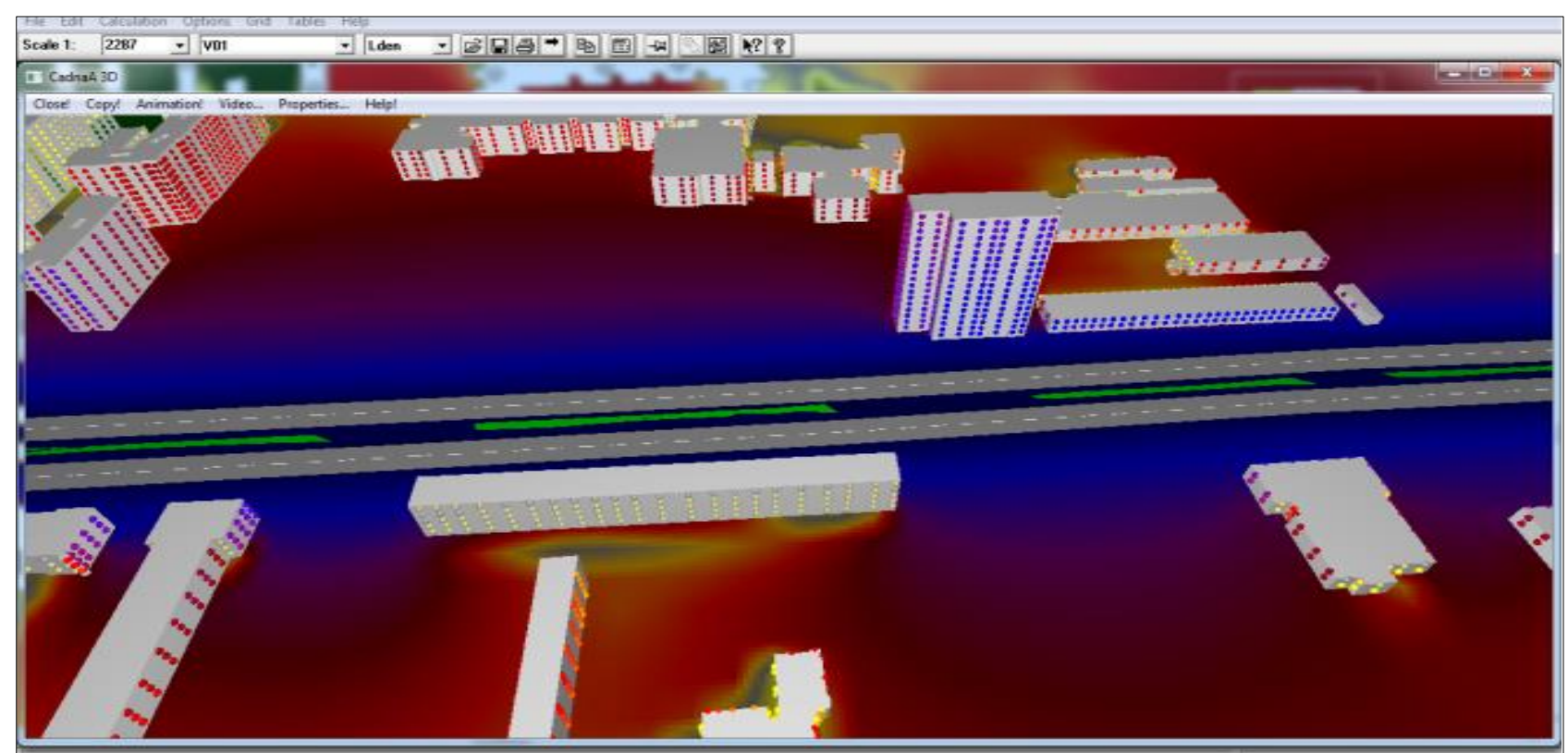

Fig. 2. Modeling area Lden - CadnaA 3D

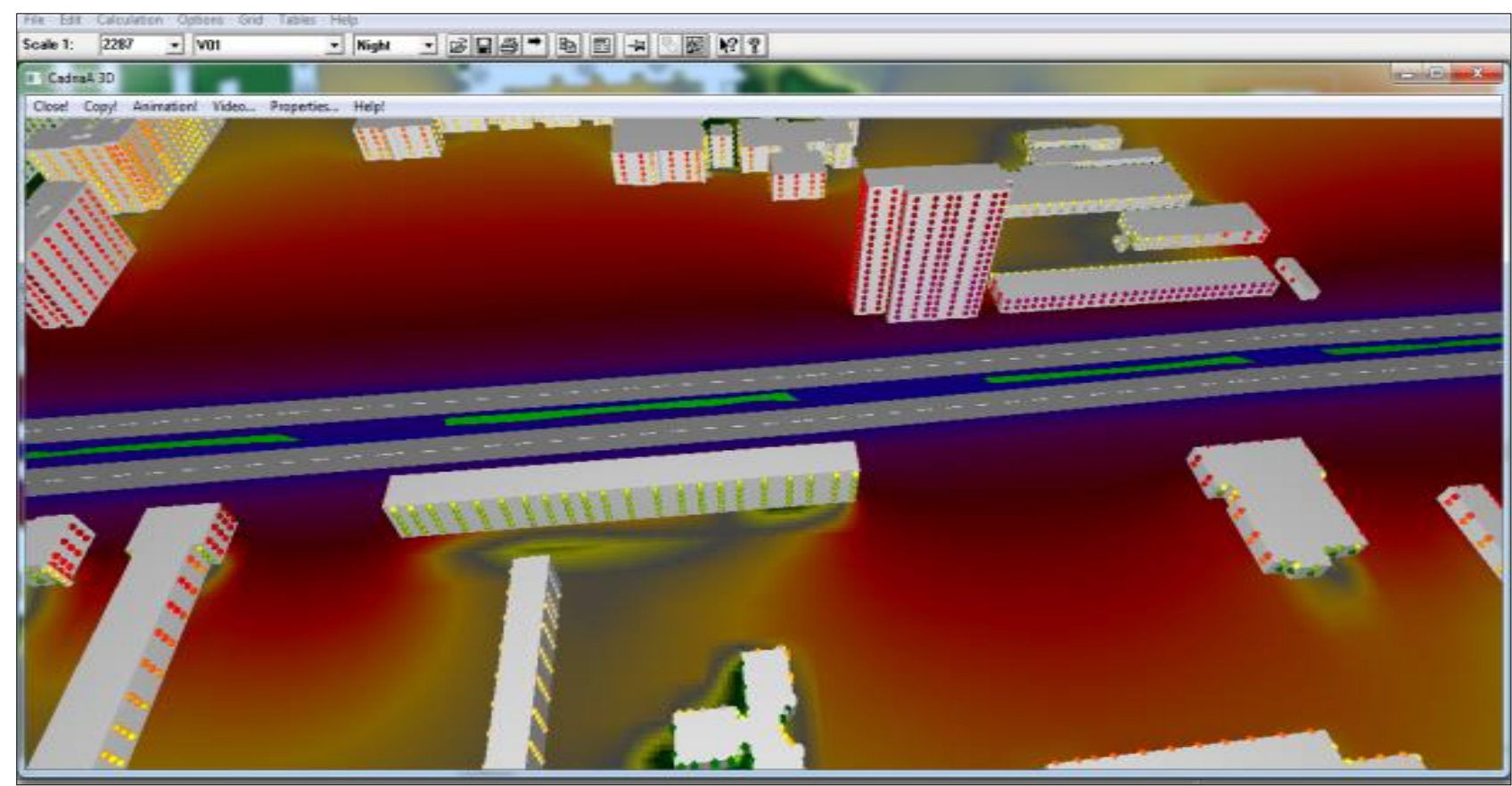

Fig. 3. Modeling area Ln - CadnaA 3D

The quality of the calculation GIS model, and also the calculation method used by CadnaA are correct and can be used for the establishing of the insertion losses of the barriers. 
Radoi, A. M.: The Establishing of the Insertion Loss of the Noise Barriers

2.2 The establishing of the insertion loss of the noise barriers using the cadnaA software

The performance of the barrier is measured through the insertion loss, defined as being the noise level difference, before and after the installation of the barrier.

In the following images, there are presented several simulations, through the placing of noise barriers in the vicinity of the road, at $4 \mathrm{~m}$ from the border of the pavement. The receiver has been chosen at $5 \mathrm{~m}$ behind the barrier and at height of 1.5 $\mathrm{m}$ off the ground. Four types of noise barriers were used: cylindrical barrier (fig. 4, option MITHRA), the T-shape barrier (fig.5, option MITHRA), the barrier inclined to the left (fig.6) and the barrier inclined to the right (fig.7), with heights of $3 \mathrm{~m}, 4.5 \mathrm{~m}, 6$ $\mathrm{m}$ and $8 \mathrm{~m}$. Usually, the road barriers are smaller than $8 \mathrm{~m}$ because of certain structural and esthetic problems.

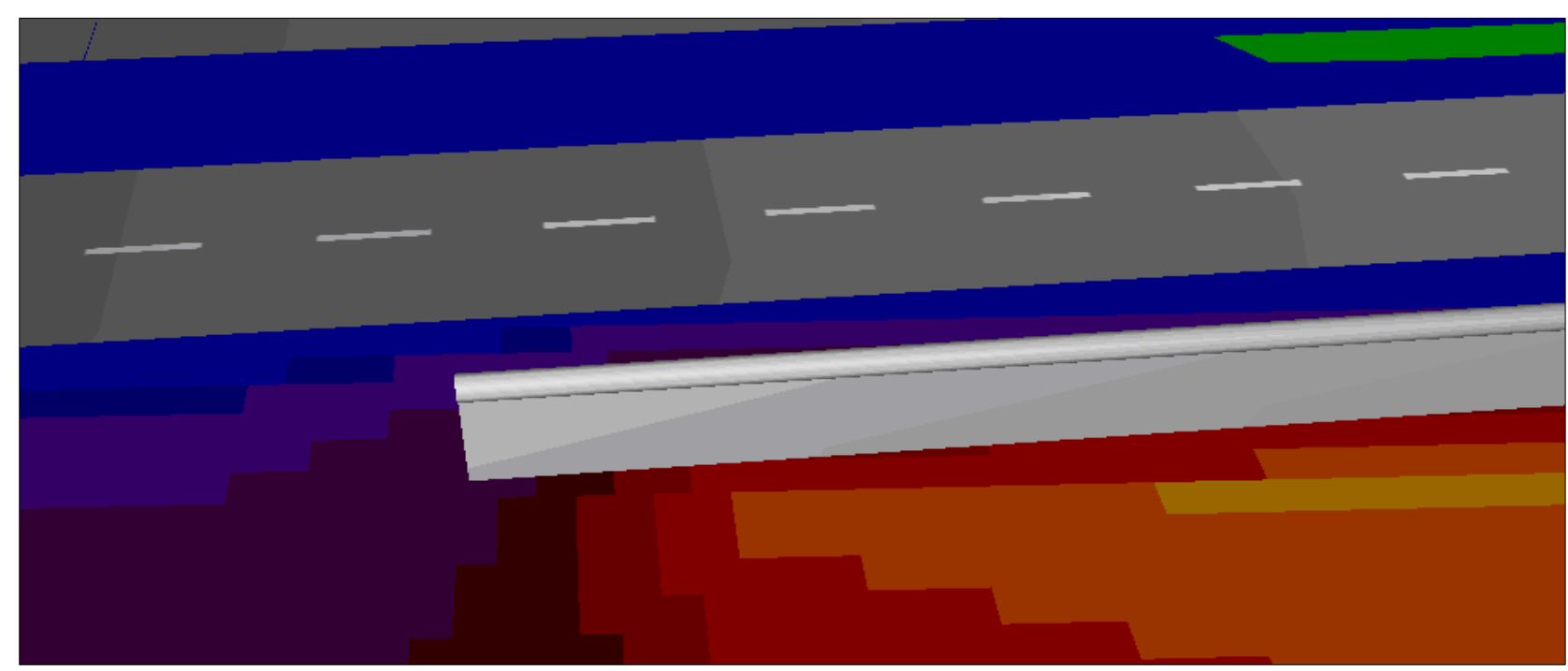

Fig. 4. Cylindrical barrier

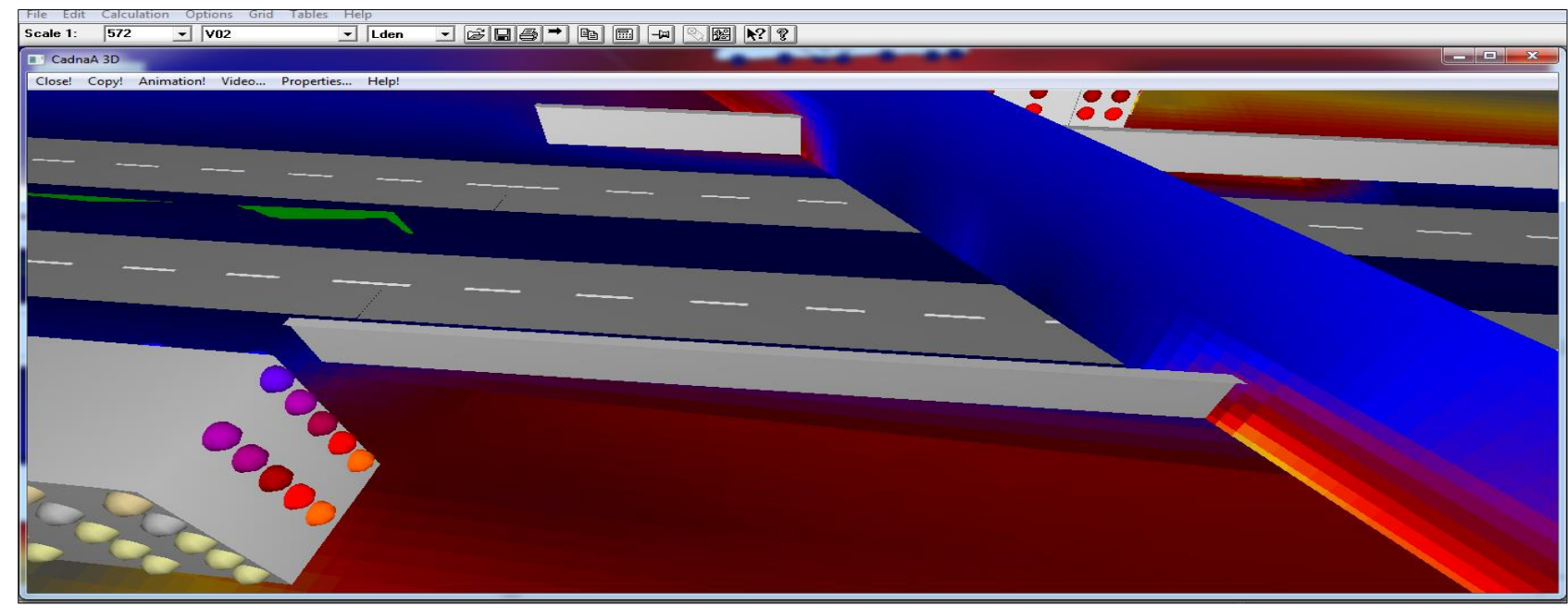

Fig. 5. T-shape barrier

The object " vertical grid" in figure 5 enables to perform grid calculations on vertical cross sections showing the noise distribution as on a vertical projection. 


\begin{tabular}{lll}
\hline DAAAM INTERNATIONAL SCIENTIFIC BOOK 2015 & pp. 173-188 & Chapter 16 \\
\hline
\end{tabular}

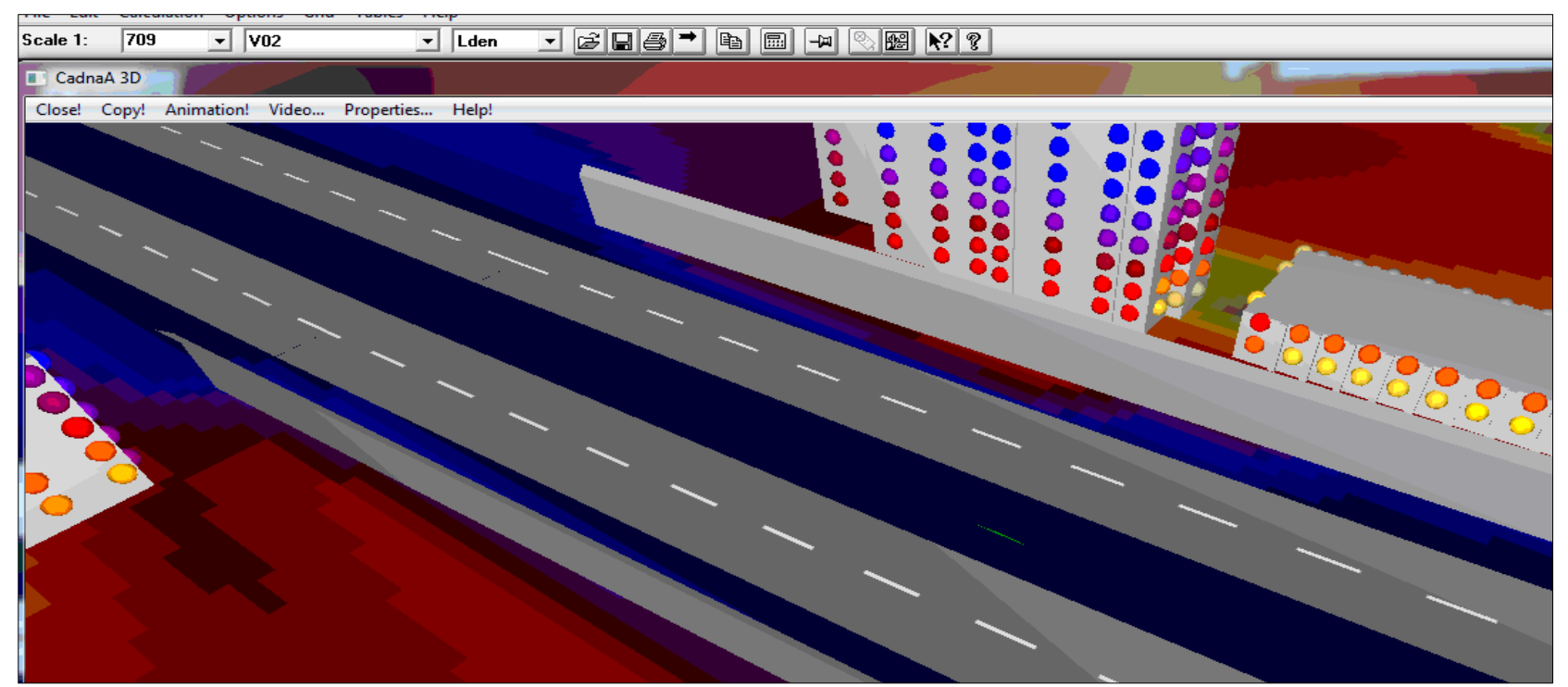

Fig. 6. The barrier inclined to the left

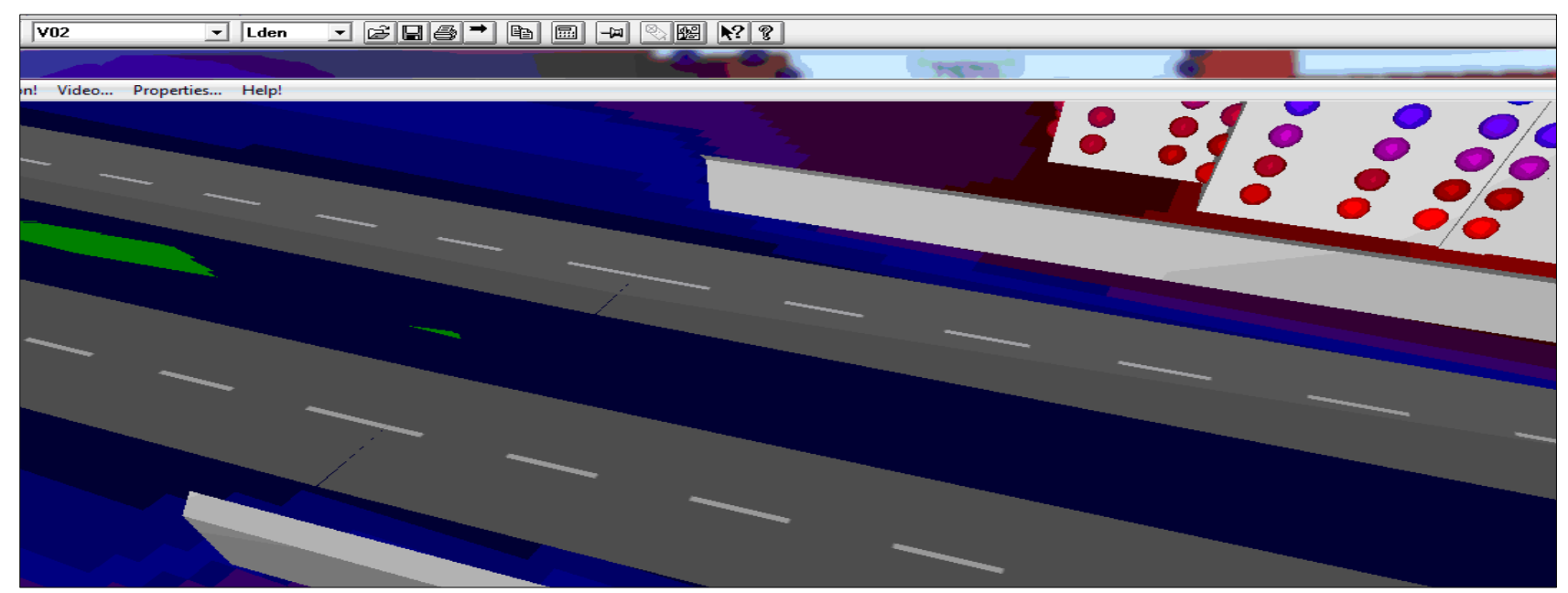

Fig. 7. The barrier inclined to the right

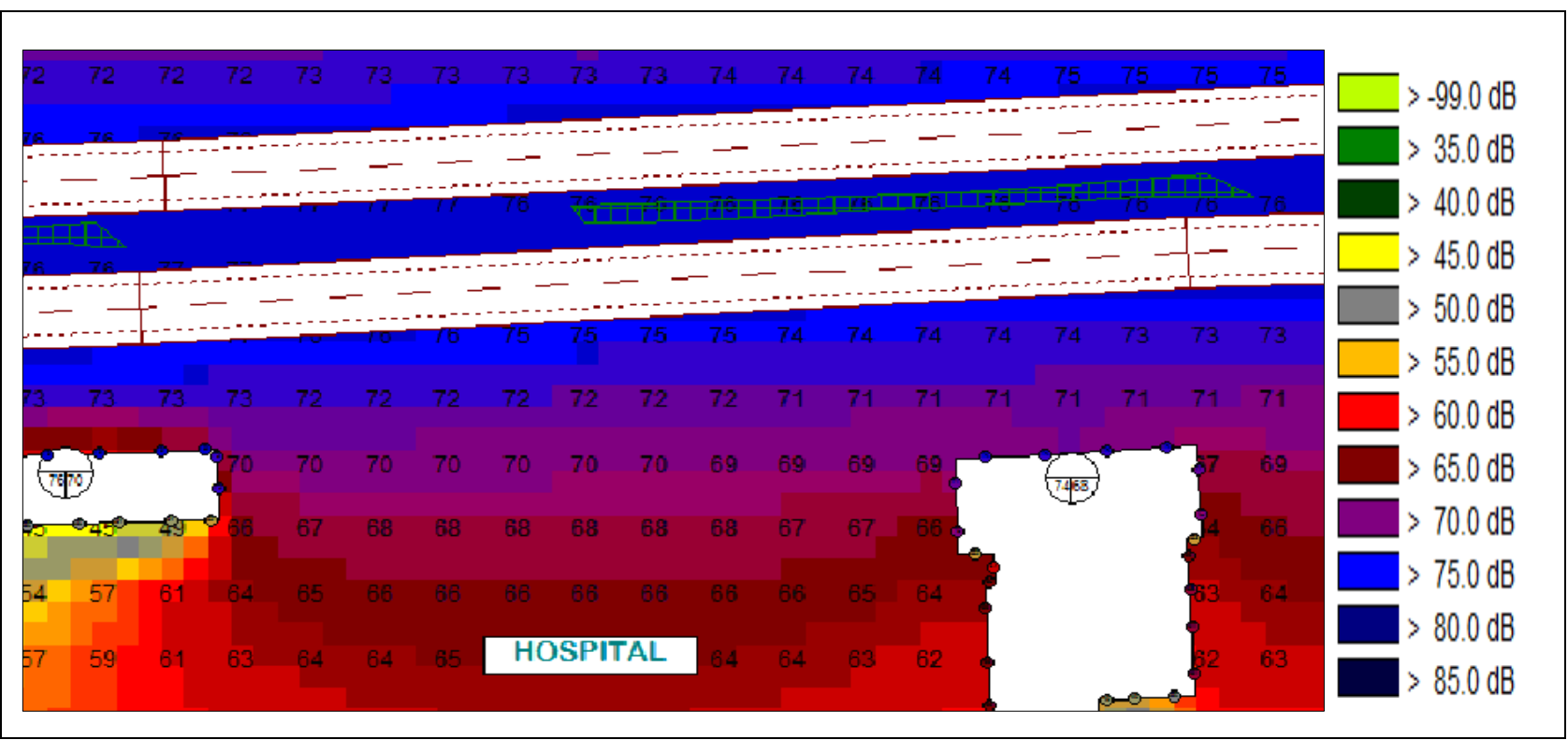

Fig. 8. Noise level without the noise barriers

Colour Legend 


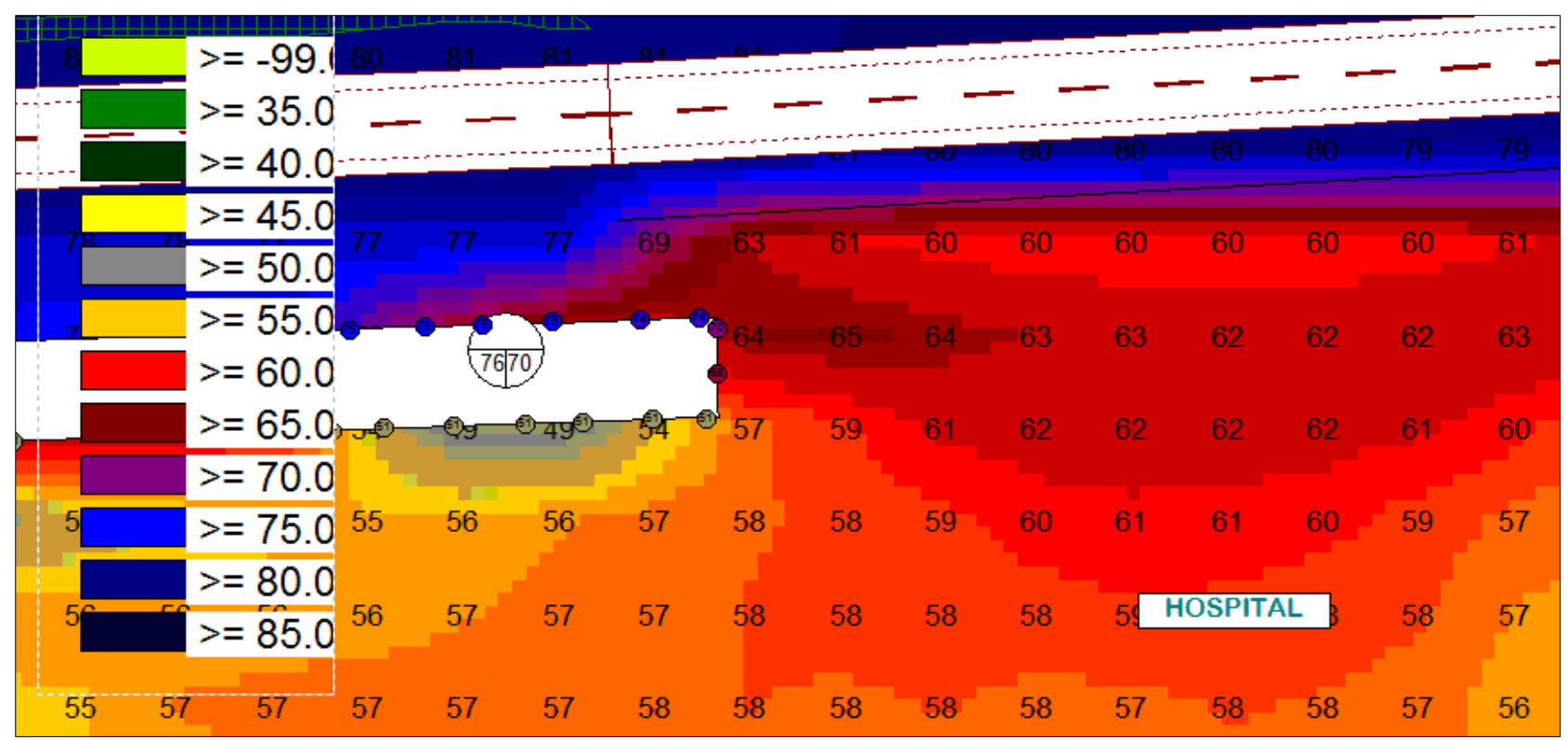

Fig. 9. Noise level with the cylindrical barriers

Figure 8 presents the noise level of the area before the installation of the noise barriers. The noise level of the area after the installation of the barriers on both sides of the road is presented in figure 9 and figure11. The barriers have the absorption coefficient $\alpha=0.84$ (very absorbing) and the reflection loss is $R L=8$. In figure 9 there are installed cylindrical barriers with the height of $8 \mathrm{~m}$ and in figure 11 there are installed barriers inclined to the left with the height of $4.5 \mathrm{~m}$. The CadnaA software has the special option MITHRA for the calculation of the noise level of these barriers.

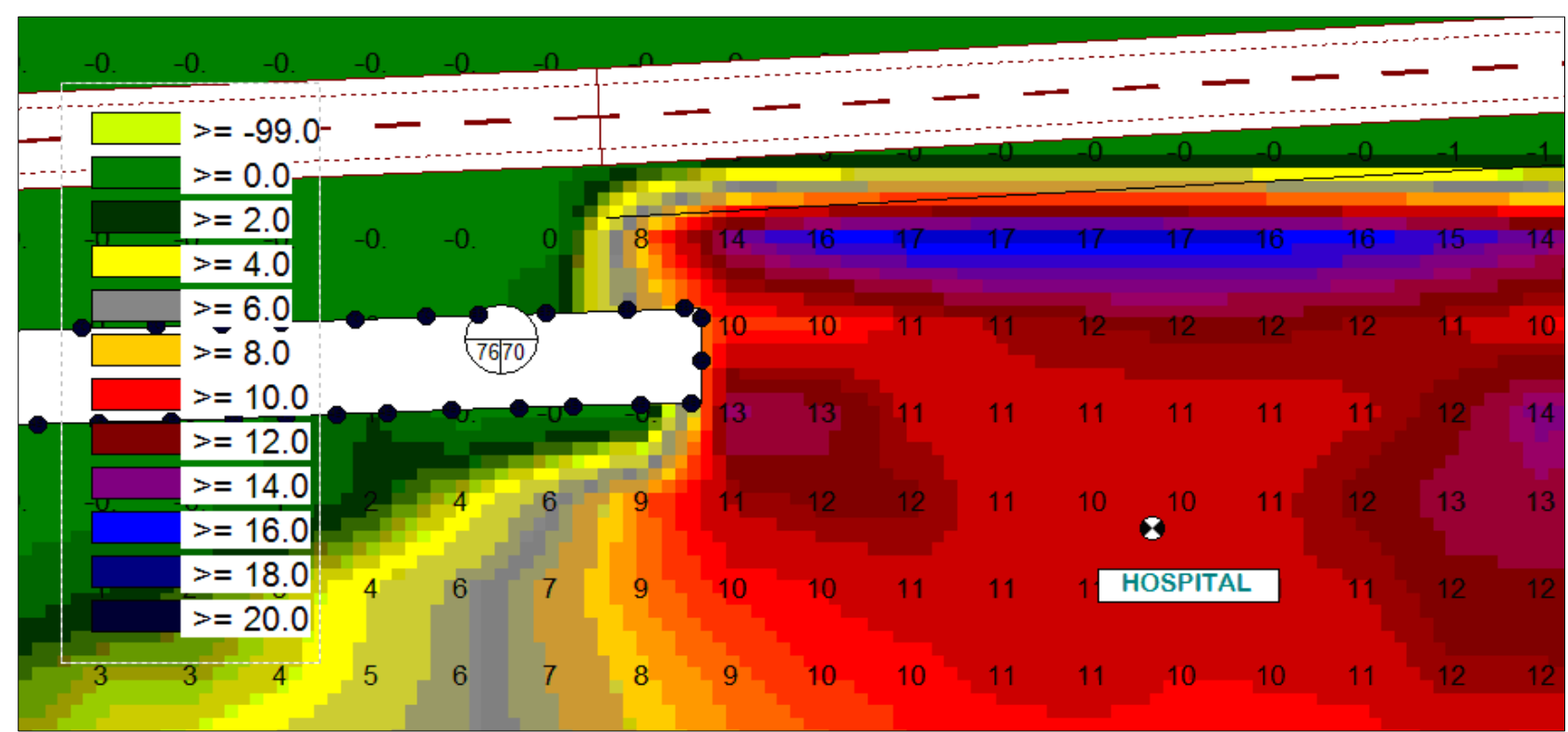

Fig. 10. The difference map

The difference map between the level noise before and after the installation of the barriers is presented in figure 10 for the cylindrical barriers with the height of $8 \mathrm{~m}$, in figure 12 for the barriers inclined to the left for the height of 4.5, in figure 13 for $\mathrm{T}$ shape barriers for the height of $3 \mathrm{~m}$ and in figure 14 for the barriers inclined to the right for the height of $6 \mathrm{~m}$. 


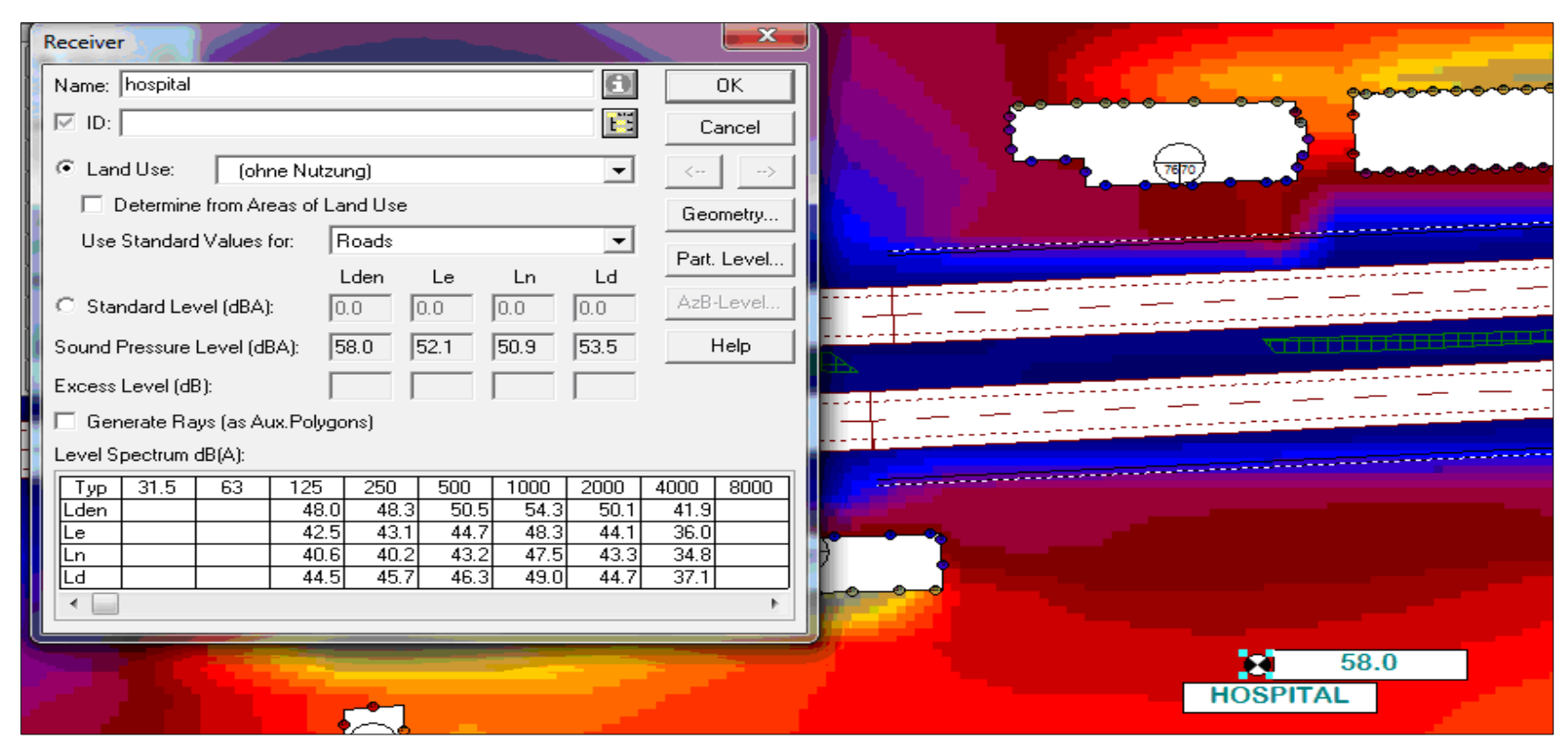

Fig. 11. Noise level with the barriers inclined to the left

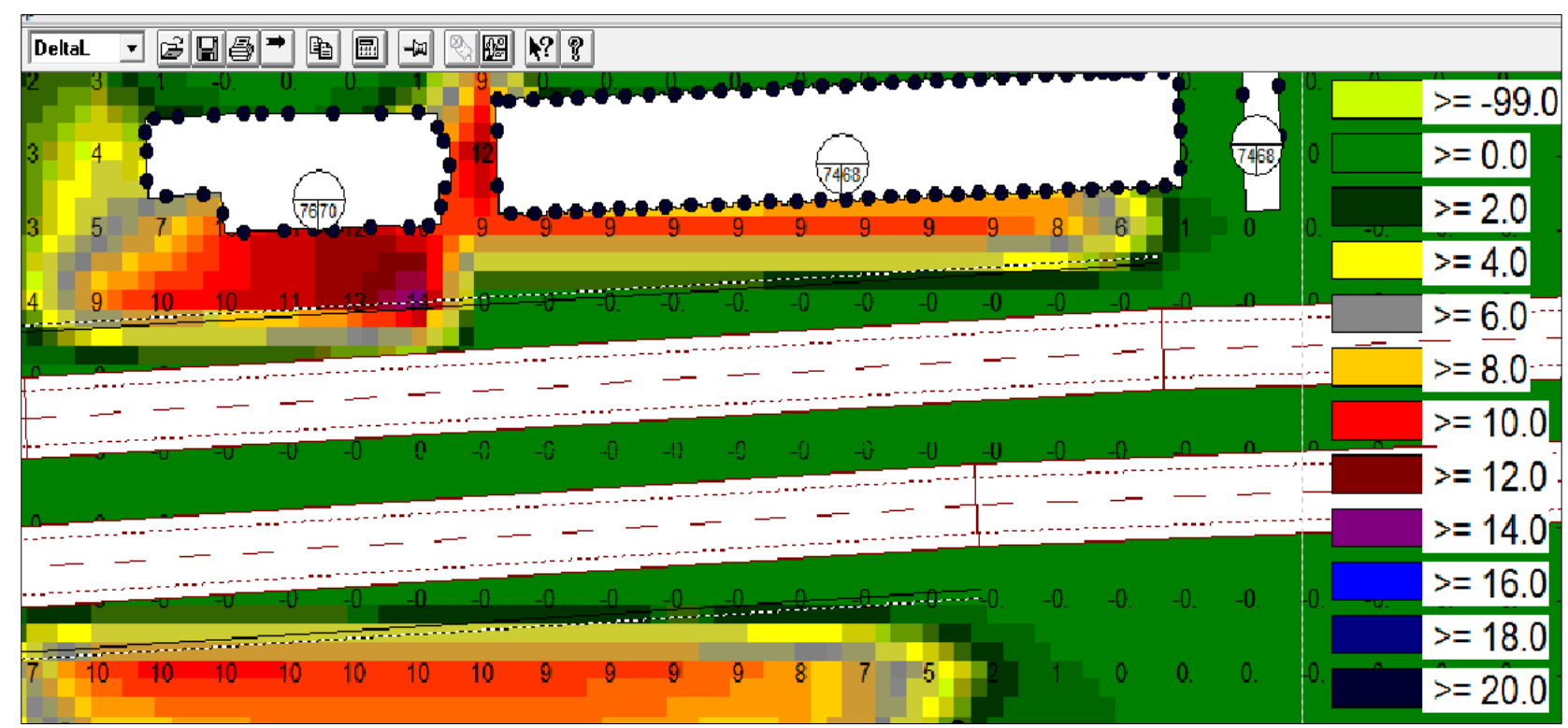

Fig. 12. The difference map

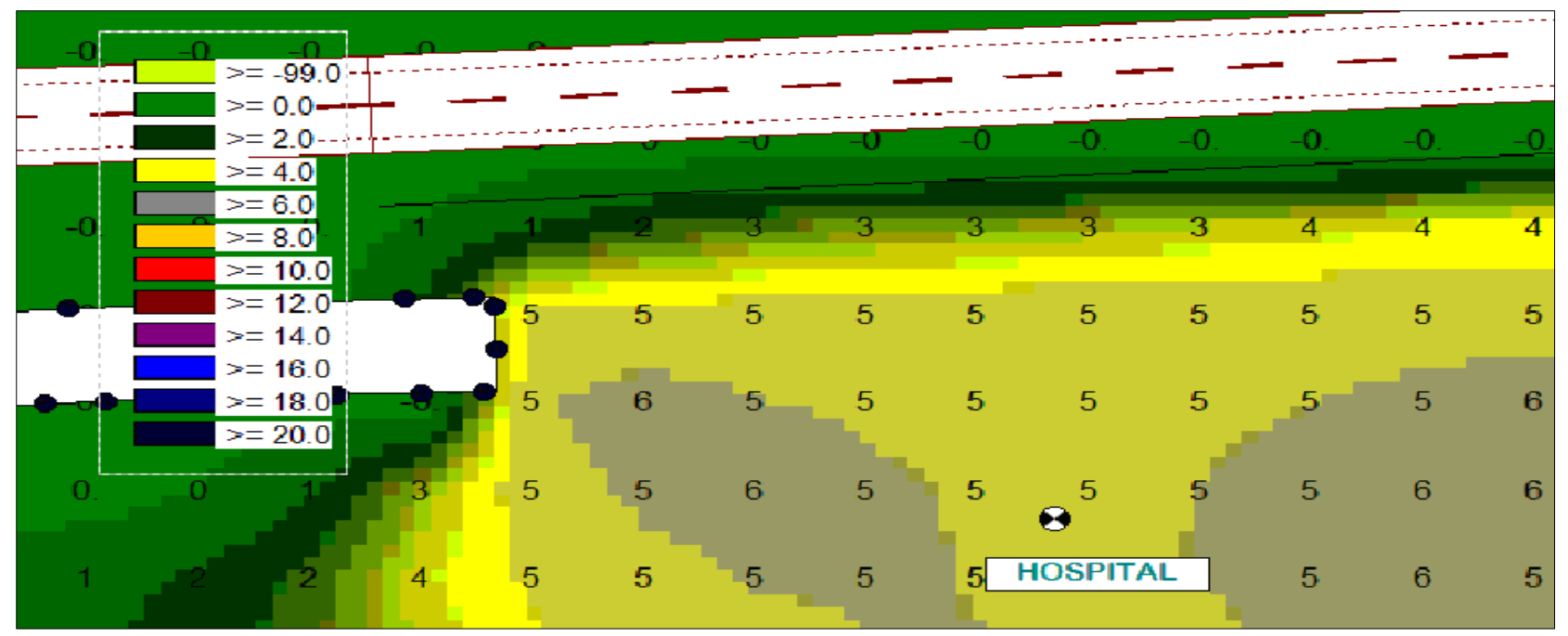

Fig. 13. The difference map 


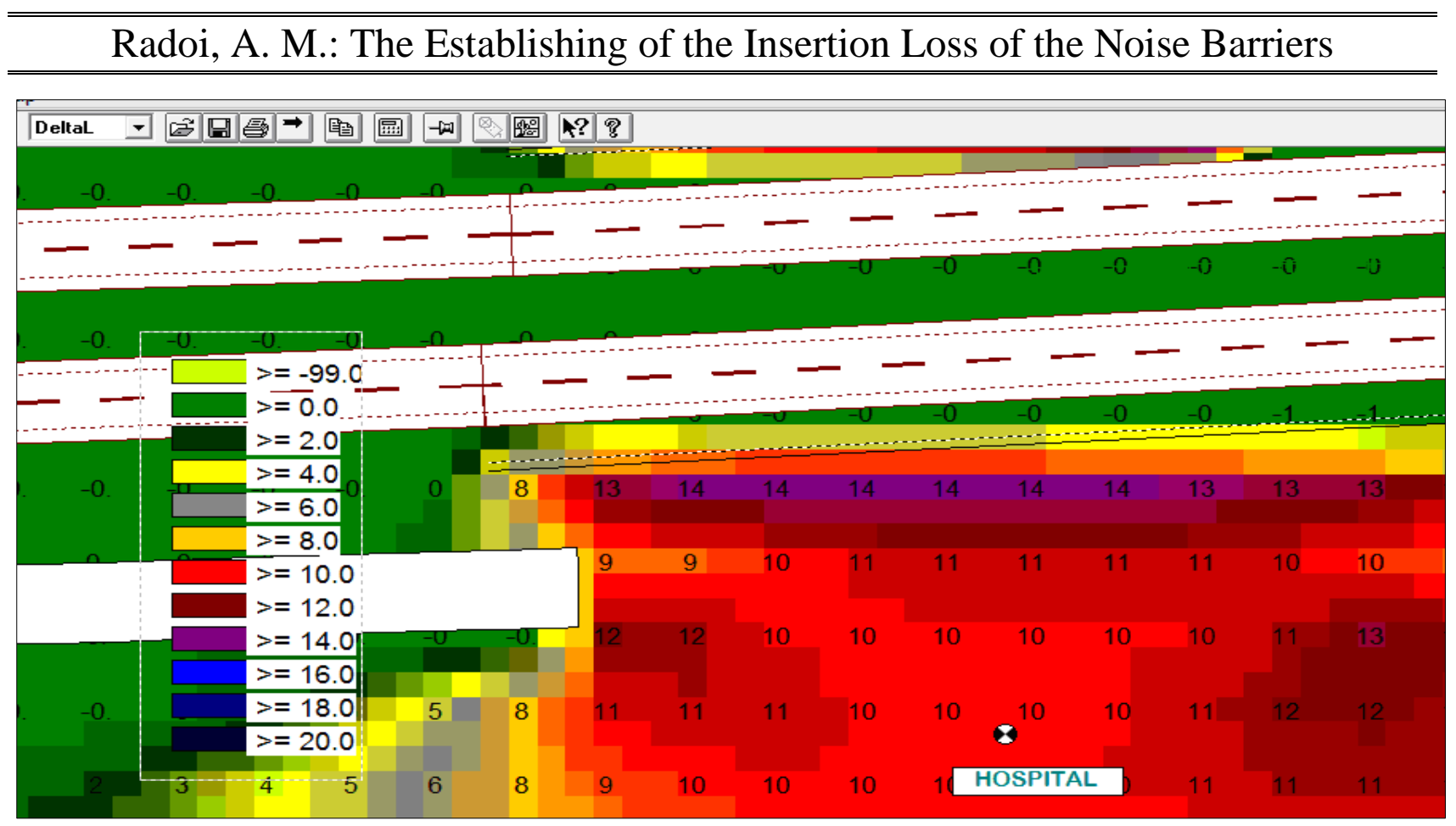

Fig. 14. The difference map

In Table 2 it is presented the insertion loss for the 4 types of barrier with the heights of $3 \mathrm{~m}, 4.5 \mathrm{~m}, 6 \mathrm{~m}$ and $8 \mathrm{~m}$.

\begin{tabular}{|c|c|c|c|c|}
\hline \multirow{2}{*}{$\mathrm{h}[\mathrm{m}]$} & \multicolumn{4}{|c|}{ INSERTION LOSS [dB(A)] } \\
\cline { 2 - 5 } & Barrier T & Cylindrical barrier & Left barrier & Right barrier \\
\hline 3 & 4 & 5 & 4 & 3 \\
\hline 4.5 & 9 & 10 & 10 & 9 \\
\hline 6 & 14 & 13 & 13 & 12 \\
\hline 8 & 17 & 16 & 16 & 15 \\
\hline
\end{tabular}

Tab. 2. The insertion loss for the 4 types of barrier

\subsection{The establishing of the insertion loss of the noise barriers using the ENC4.1} software (Engineering Noise Control)

The calculation of the insertion loss is performed after the installation of the finite length barrier between a source and a receiver. It is chosen the special model of diffraction of the barrier from a total of 4 different options: Maekawa method (figure 15), Kurze \& Anderson method (figure 16), ISO 9613-2 method (figure 17) and Menounou method (figure18).

The calculation of the barrier includes the effects of the land of each one of its sides and excludes the effect of the soil in case of lack of the barrier. 


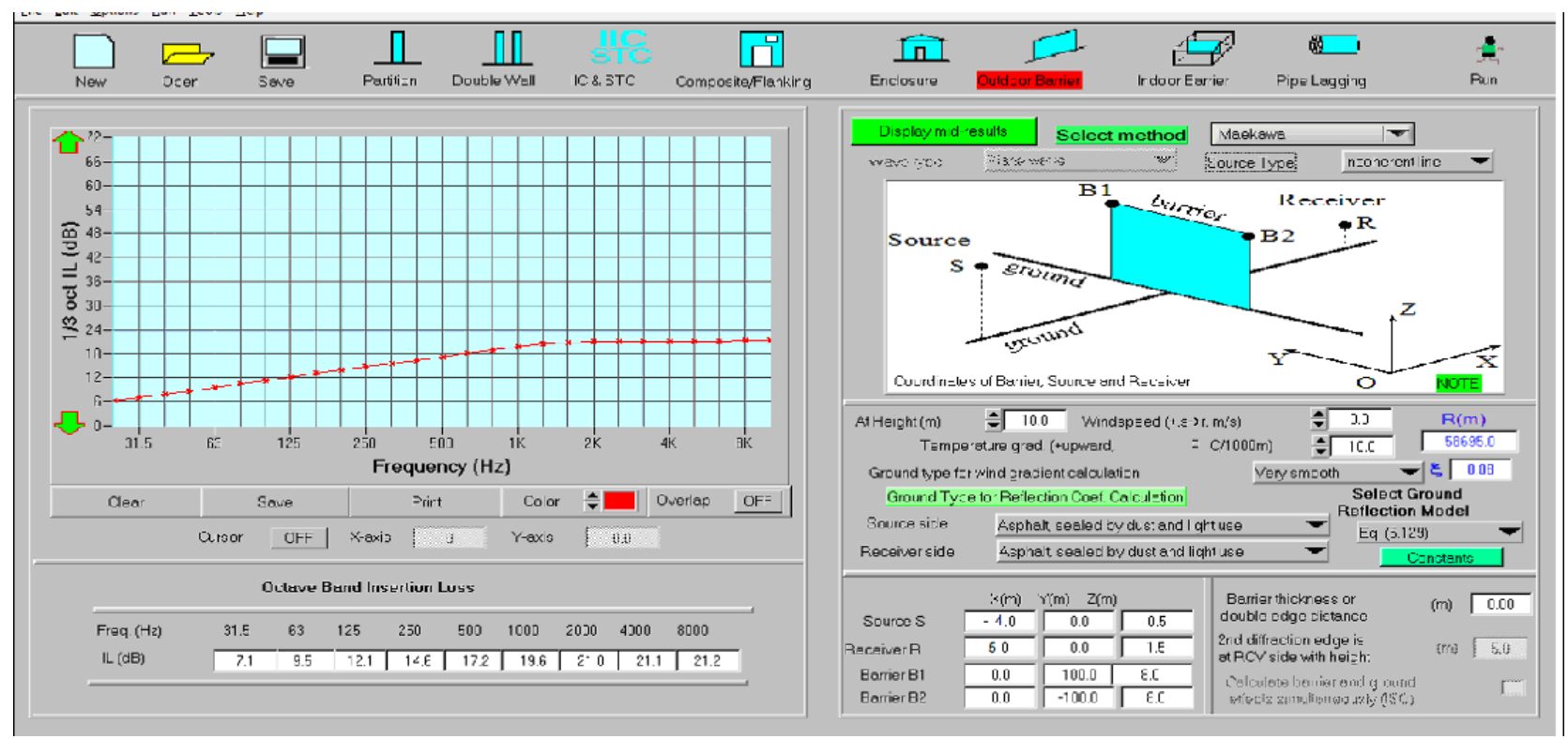

Fig. 15. Maekawa method

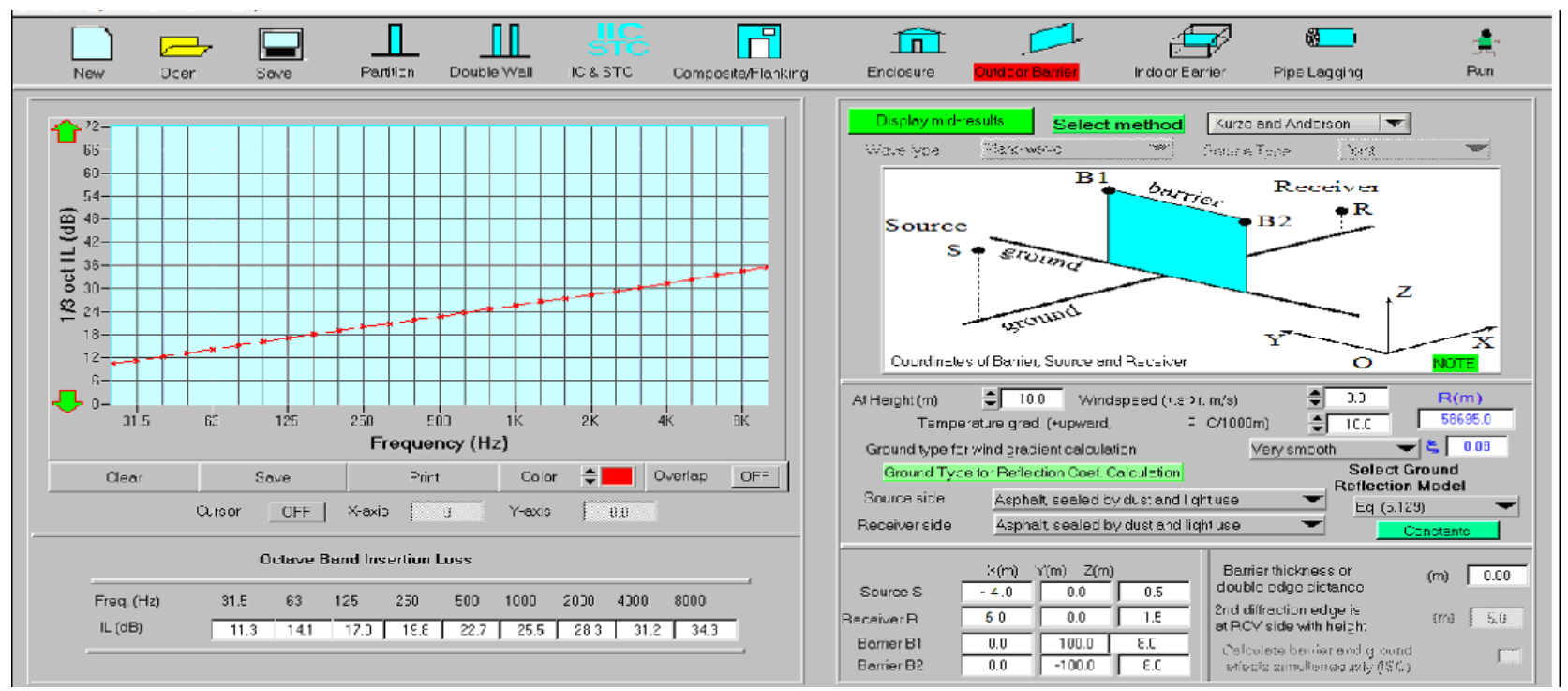

Fig. 16. Kurze \& Anderson method

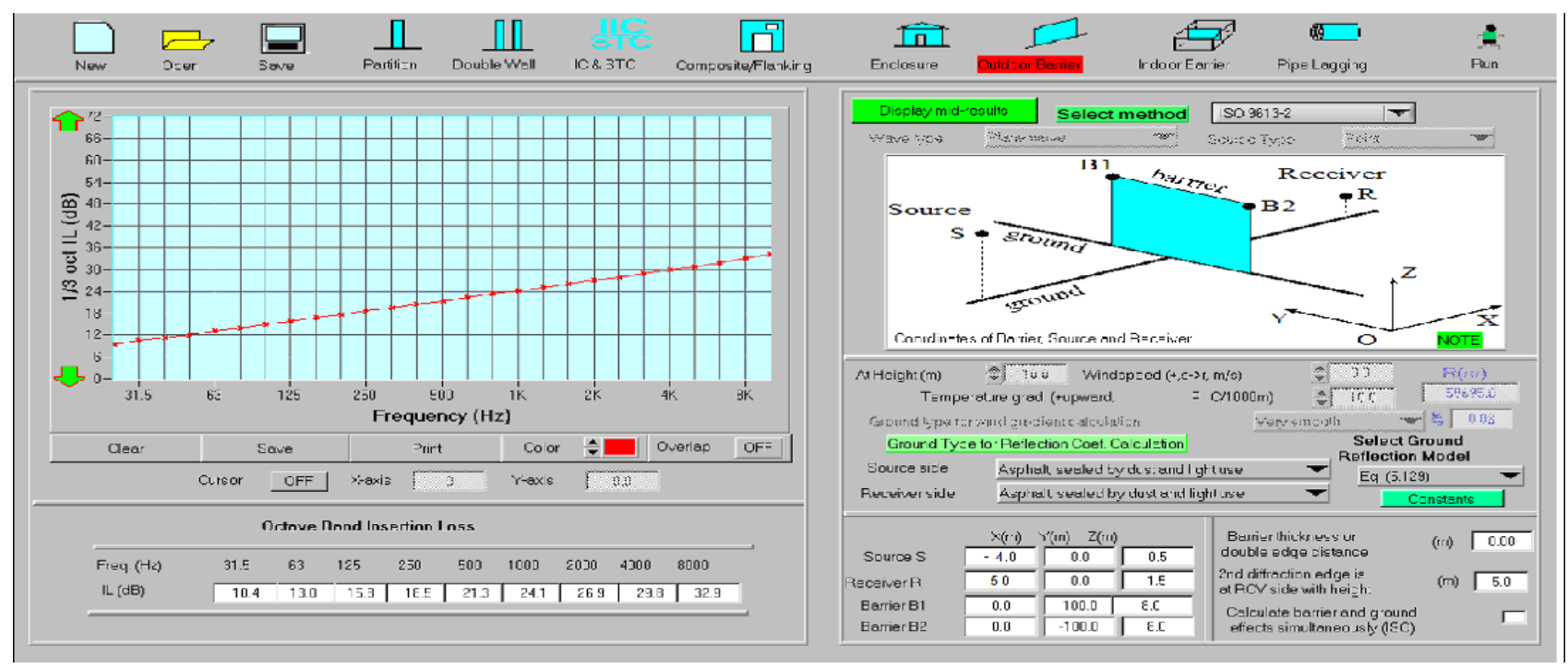

Fig. 17. ISO 9613-2 method 


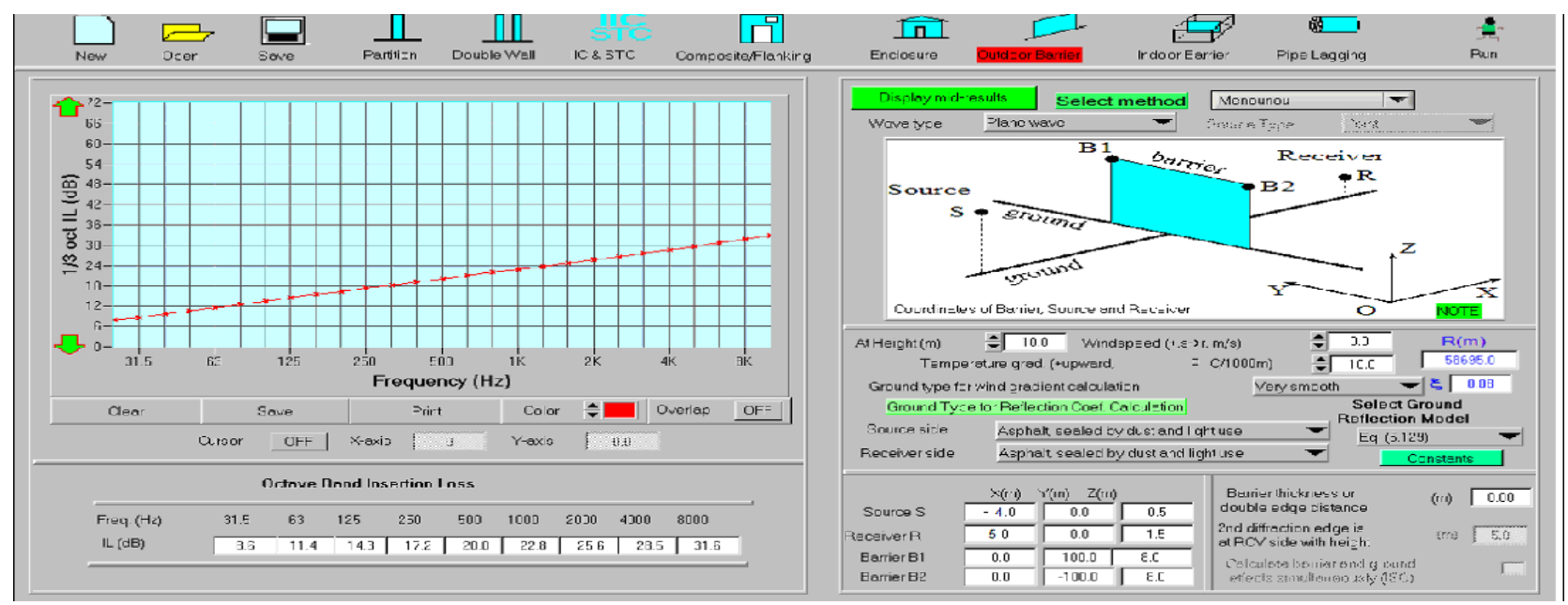

Fig. 18. Menounou method

In figure 15-18 there are presented the insertion loss for barriers with heights of $8 \mathrm{~m}$, installed at a distance of $4 \mathrm{~m}$ from the noise source and at a distance of $5 \mathrm{~m}$ from the receiver.

In an analogue manner, it is established the insertion loss of the barriers with heights of $3 \mathrm{~m}, 4.5 \mathrm{~m}$ and $6 \mathrm{~m}$.

In table 3, it is presented the insertion loss of the barriers with heights of $3 \mathrm{~m}, 4.5 \mathrm{~m}, 6$ $\mathrm{m}$ and $8 \mathrm{~m}$, at a frequency of $500 \mathrm{~Hz}$.

\begin{tabular}{|c|c|c|c|c|}
\hline \multirow{2}{*}{$\mathrm{h}[\mathrm{m}]$} & \multicolumn{4}{|c|}{ INSERTION LOSS [dB(A)] } \\
\cline { 2 - 5 } & $\begin{array}{c}\text { Maekawa } \\
\text { (Incoherent line) }\end{array}$ & $\begin{array}{c}\text { Kurze and Anderson } \\
\text { (Point) }\end{array}$ & $\begin{array}{c}\text { ISO 9613-2 } \\
\text { (Point) }\end{array}$ & $\begin{array}{c}\text { Menounou } \\
\text { (Point) }\end{array}$ \\
\hline 3 & 8 & 12.5 & 12.7 & 13.4 \\
\hline 4.5 & 12.2 & 17.2 & 16.9 & 16.7 \\
\hline 6 & 14.7 & 20 & 19.2 & 18.5 \\
\hline 8 & 17.2 & 22.7 & 21.3 & 20 \\
\hline
\end{tabular}

Tab. 3. The insertion loss of the barriers

\subsection{The establishing of the insertion loss of the noise barriers using formulas}

The insertion loss of the barrier depends on the road difference between the direct sound road and the diffracted one, the height and dimensions of the screen, the distance between the source and the reception point, the reflection factor of the screen surface, the frequency (the acoustical spectrum of the source).

The International Standards Calculate The Diffraction Above The Upper Edge And Around The Vertical Edge Of The Barrier. The Double Diffraction Over The Thick Barriers May Be Also Calculated.

The International Standard ISO 9613-2 Specifies A General Method For The Calculation Of The Attenuation of the noise which is dispersed in free field and 
includes the presence of the noise barriers. The attenuation of the barrier may be calculated with the equation (7) according to ISO 9613-2:

$$
\mathrm{Dz}=10 \cdot \log \{3+(\mathrm{C} 2 / \lambda) \cdot \mathrm{C} 3 \cdot \mathrm{z} \cdot \mathrm{Kmet}\}
$$

where

C2 is equal to 20, and includes the effect of ground reflections

$\mathrm{C} 3=\left[1+(5 \lambda / \mathrm{e})^{2}\right] /\left[1 / 3+(5 \lambda / \mathrm{e})^{2}\right]$ for double diffraction

$\mathrm{C} 3=1$ for single diffraction; $\mathrm{e}=$ the distance between the tops of two most effective screens; $\lambda=$ the wavelength

Kmet is the correction factor for meteorogical effects

Kmet $\left.=\exp \left\{-(1 / 2000)[(d s s \cdot d s r \cdot d) / 2 z)^{1 / 2}\right]\right\}$ for $z>0 ;$ Kmet $=1$ for $z \leq 0$

dss $=$ distance source-screen $; \quad \mathrm{dsr}=$ distance screen-receiver

$\mathrm{a}$ is the component distance parallel to the barrier edge between source and receiver $\mathrm{z}=\left[(\mathrm{dss}+\mathrm{dsr}+\mathrm{e})^{2}+\mathrm{a}^{2}\right]^{1 / 2}-\mathrm{d}$ the path lenght difference

If the line of sight between the source and receiver passes above the top edge of the barrier, $\mathrm{z}$ is given a negative sign.

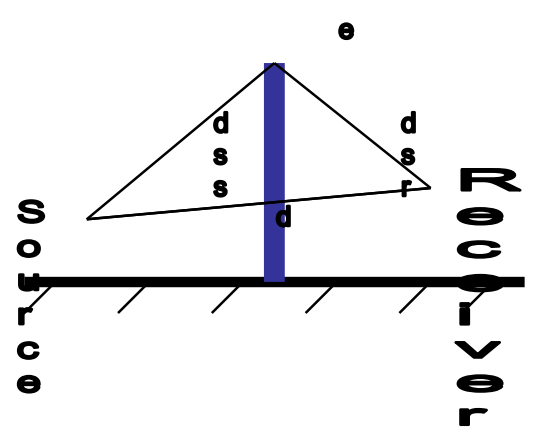

Noise barrier

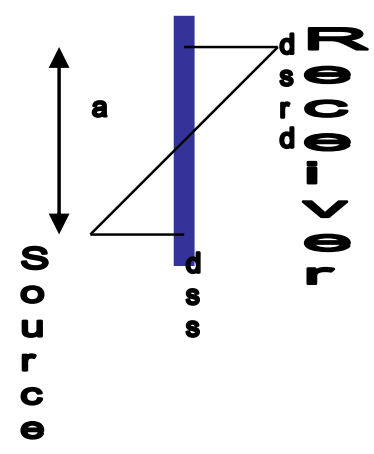

Noise barrier

$\mathrm{Dz}=10 \cdot \log [3+(20 / \lambda) \cdot \mathrm{z}] ; \mathrm{c}=343,1 \mathrm{~m} / \mathrm{s}\left(\right.$ at $\left.20^{\circ} \mathrm{C}\right) ; \mathrm{f}=500 \mathrm{~Hz} ; \lambda=0.68 \mathrm{~m}$

Case: $\underline{\mathrm{h}=3 \mathrm{~m}}, \mathrm{z}=\delta=0.86 \mathrm{~m}, \mathrm{~d}=9.05 \mathrm{~m}, \mathrm{dss}=4.71 \mathrm{~m}, \mathrm{dsr}=5.2 \mathrm{~m}$

$$
\mathrm{Dz}=14.5 \mathrm{~dB}
$$

Case: $\underline{\mathrm{h}=4.5 \mathrm{~m}}, \mathrm{z}=\delta=2.35 \mathrm{~m}, \mathrm{~d}=9.05 \mathrm{~m}, \mathrm{dss}=5.6 \mathrm{~m}, \mathrm{dsr}=5.8 \mathrm{~m}$

$$
\mathrm{Dz}=18.5 \mathrm{~dB}
$$


Case $: \underline{\mathrm{h}=6 \mathrm{~m}}, \mathrm{z}=\delta=4.47 \mathrm{~m}, \mathrm{~d}=9.05 \mathrm{~m}, \mathrm{dss}=6.8 \mathrm{~m}, \mathrm{dsr}=6.72 \mathrm{~m}$

$$
\mathrm{Dz}=21.28 \mathrm{~dB}
$$

Case $: \underline{\mathrm{h}=8 \mathrm{~m}}, \delta=7.65 \mathrm{~m}, \mathrm{~d}=9.05 \mathrm{~m}, \mathrm{dss}=8.5 \mathrm{~m}, \mathrm{dsr}=8.2 \mathrm{~m}$

$$
\mathrm{Dz}=23.57 \mathrm{~dB}
$$

If the source is linear, the attenuation of the screen is calculated with the relation of Kurze:

$$
\Delta \mathrm{L}=15 \cdot \log \left[\frac{\sqrt{2 \pi N}}{\tanh \sqrt{2 \pi N}}\right]-10 \cdot \log \left(2 e^{-\frac{h}{2 \lambda}}+1\right)+5 \quad[d B]
$$

$\mathrm{N}= \pm 2\left(\delta_{0} / \lambda\right)= \pm 2\left(\mathrm{f} \delta_{0} / \mathrm{c}\right) ; \mathrm{f}=500 \mathrm{~Hz} ; \mathrm{c}=343,1 \mathrm{~m} / \mathrm{s}\left(\right.$ at $\left.20^{\circ} \mathrm{C}\right) ; \mathrm{N}=$ number of Fresnel

Case: $\underline{\mathrm{h}=3 \mathrm{~m}}, \delta=0.86 \mathrm{~m}, \mathrm{~N}=2.52, \mathrm{~d}=9.05 \mathrm{~m}, \mathrm{dss}=4.71 \mathrm{~m}, \mathrm{dsr}=5.2 \mathrm{~m}$

$$
\Delta \mathrm{L}=3,24 \mathrm{~dB}
$$

Case: $\underline{\mathrm{h}=4.5 \mathrm{~m}}, \delta=2.35 \mathrm{~m}, \mathrm{~N}=6.88, \mathrm{~d}=9.05 \mathrm{~m}, \mathrm{dss}=5.6 \mathrm{~m}, \mathrm{dsr}=5.8 \mathrm{~m}$

$$
\Delta \mathrm{L}=12 \mathrm{~dB}
$$

Case: $\underline{\mathrm{h}=6 \mathrm{~m}}, \delta=4.47 \mathrm{~m}, \mathrm{~N}=13.10, \mathrm{~d}=9.05 \mathrm{~m}, \mathrm{dss}=6.8 \mathrm{~m}, \mathrm{dsr}=6.72 \mathrm{~m}$

$$
\Delta \mathrm{L}=19,32 \mathrm{~dB}
$$

Case $: \underline{h=8 \mathrm{~m}}, \delta=7.65 \mathrm{~m}, \mathrm{~N}=22.5, \mathrm{~d}=9.05 \mathrm{~m}, \mathrm{dss}=8.5 \mathrm{~m}, \mathrm{dsr}=8.2 \mathrm{~m}$

$$
\Delta \mathrm{L}=21,16 \mathrm{~dB}
$$

Table 4 presents the insertion loss of the barriers for the 3 methods.

There were not registered in the table the models for the noise point source.

\begin{tabular}{|c|c|c|c|c|c|c|}
\hline \multirow{2}{*}{$\mathrm{h}[\mathrm{m}]$} & \multicolumn{6}{|c|}{ INSERTION LOSS [dB(A)] } \\
\cline { 2 - 7 } & $\begin{array}{c}\text { Barrier } \\
\mathrm{T}\end{array}$ & $\begin{array}{c}\text { Cylindrical 1 } \\
\text { barrier }\end{array}$ & $\begin{array}{c}\text { Left } \\
\text { barrier }\end{array}$ & $\begin{array}{c}\text { Right } \\
\text { barrier }\end{array}$ & $\begin{array}{c}\text { Method 2 } \\
\text { Maekawa } \\
\text { (Incoherent } \\
\text { line) }\end{array}$ & $\begin{array}{c}\text { Kurze } \\
\text { (source line) }\end{array}$ \\
\hline 3 & 4 & 5 & 4 & 3 & 8 & 3.24 \\
\hline 4.5 & 9 & 10 & 10 & 9 & 12.2 & 12 \\
\hline 6 & 14 & 13 & 13 & 12 & 14.7 & 19.32 \\
\hline 8 & 17 & 16 & 16 & 15 & 17.2 & 21.16 \\
\hline
\end{tabular}

Tab. 4. Insertion loss of the barriers for the 3 methods 
The differences between the three methods are present but not drastic, as shown in Table 4. As expected, the growth of barrier height leads to an increase of barrier attenuation. It is interesting to present the maximum and minimum values of this increase, for each calculation method, when raising the height of the barrier from 3 to $8 \mathrm{~m}$. Kurze's formula usually gave the highest value of barrier attenuation, due to the fact that does not include ground, air and other absorption effects. Maekawa and Kurze calculations are always overestimating the noise reduction, while CadnaA, that considers much more parameters, seems to furnish a more realistic prediction.

The modelling and calculation software, CadnaA, has the following strong points compared to the other 2 methods: it allows the estimation of the number of houses, hospitals, schools in a certain area, which are exposed to a specified value of a noise indicator; it allows mediation on a certain period of time; it allows the efficient verification of the calculation conditions permite; it allows the performance of a mathematical model (GIS) of the buildings and of the noise source and the installation of the noise barriers in this model; it considers the form and type of the noise barrier; the modelling shows the current situation, a future situation or a forecast in the terms of a noise indicator; the modelling shows the exceeding of a limit value; the software allows the efficient verification of the calculation conditions.

The Directive 2002/49/EC (END) and the related documents recommend (for estimations) that the noise level values can be established through modelling only with the specialized software. The guide for good practices: The WG-AEN recommendations are for the mapping of the noise through modelling.

\section{Conclusions}

- There is a strong body of evidence to support the use of barriers as an effective method of abating transportation noise.

- The best descriptor of barrier performance is its insertion loss, which is the difference in the noise environment before and after the barrier is constructed.

- The most common values for A-weighted insertion loss range between about 5 and $12 \mathrm{~dB}$, but values between 3 and $22 \mathrm{~dB}$ are also often found.

- The noise reduction due to the insertion of an acoustical barrier is studied in terms of different calculation methods. Results of attenuation obtained from formula Kurze, software ENC and predictive software CadnaA have been compared, varying the height of the hypothetic barrier. Kurze's formula usually gave the highest value of barrier attenuation, due to the fact that does not include ground, air and other absorption effects. Maekawa and Kurze calculations are always overestimating the noise reduction, while CadnaA, that considers much more parameters, seems to furnish a more realistic prediction.

- Each one of three methods present advantages and disadvantages which influence the results of the calculations. The ENC 4.1 software and the calculation relations are easier to use compared to the Cadna A4.3 software which needs a special ability. CadnaA noise modeling software package is more accurate and effective than ENC model software and than the calculation relations. 
- Barrier height and proximity of source and receiver are of fundamental importance to the insertion loss provided by a barrier.

- The use of absorbing material is particularly important in this type of application. • The material used to construct barriers must be such that there is sufficient transmission loss of sound through the wall. It is also important that there be no significant air gaps in the structure nor between the barrier and the ground.

- Further applications of this study could be related to field measurement validation, in order to calibrate the software calculation and to test which methods is more reliable. The eventual results could be used to properly design the barrier that is going to be installed.

\section{References}

Hansen, C.H. and Bies, D.A. (2009) Engineering Noise Control:Theory and Practice, Fourth Edition, CRC Press

Kurze,U..J. (1974) Noise reduction by barriers. The Journal of the Acoustical Society of America,Vol.55(3),1974, pp.504-518

Karantonis , P., Gowen,T., and Simon, M.(2010) Further Comparison of Traffic Noise Predictions Using the CadnaA and SoundPLAN Noise. Proceedings of 20th International Congress on Acoustics, ICA 2010

Walerian, E., Janczur, R., Czechowicz, M.( 2011) Efficiency of screen application in built-up area. Elsevier, Applied Acoustics, Volume72, Issue 8, pp.511-521

Daigle, G.A.( 2010) Effectiveness of noise barriers. Inter.noise, Lisbon, Portugal Harrison, C.C., Fyfe, K.R., and Cremers,L.J. Insertion Loss Characteristics of Barriers and Berms. Department of Mechanical Engineering,University of Alberta Shukla, A.K., Jain, S.S., Parida, M., Srivastava , J.B.(2009) Performance of FHWA model for predicting traffic noise: A case study of metropolitan city, Lucknow (India), Transport, pp.234-240

Samaneh M.B. Fard, Kessissoglou,N., Samuels, S., Burgess, M.(2013) Numerical study of noise barrier designs . Proceedings of Acoustics 2013-Victor Harbor, Australian Acoustical Society

Hutchins D.A., Jones H.W., Russell L.T.(1984) Model Studies of Barrier Performance in the Presence of Ground Surface.Part.I- Thin Perfectly Reflecting Barriers, J.Acoust.Soc.Am.75(6), pp.1807-1816

Ishizuka T., Fujiwara F.(2004) Performance of noise barriers with various edge shapes and acoustical conditions, Applied Acoustics, Vol.65, No.2, pp.125-141

Crocker M.J.(2007) Handbook of Noise and Vibration Control. pp.1455-1465

Tronchin L.(2013) On the acoustic efficiency of road barriers: The Reflection

Index, International Journal of Mechanics, Issue 3, Vol. 7, pp 318-326

DataKustik GmbH (2012) CadnaA -Reference Manual

Order no. 119/2014 of the Ministry of Health

ISO 9613-2: Acoustics- Attenuation of sound during propagation outdoors -Part 2:

General method of calculation 